\title{
Synthesis of ciprofloxacin-conjugated poly (L-lactic acid) polymer for nanofiber fabrication and antibacterial evaluation
}

This article was published in the following Dove Press journal:

International Journal of Nanomedicine

26 March 2014

Number of times this article has been viewed

\author{
Sharad P Parwe \\ Priti N Chaudhari \\ Kavita K Mohite \\ Balaji S Selukar \\ Smita S Nande \\ Baijayantimala Garnaik \\ Polymer Science and Engineering \\ Division, National Chemical \\ Laboratory, Pune, India
}

Correspondence: Baijayantimala Garnaik Polymer Science and Engineering Division, National Chemical Laboratory, Pune 4I I008, Maharashtra, India

Tel +9l 2025902304

Fax +9| 2025902615

Email b.garnaik@ncl.res.in

\begin{abstract}
Ciprofloxacin was conjugated with polylactide (PLA) via the secondary amine group of the piperazine ring using PLA and 7-(4-(2-Chloroacetyl) piperazin-1-yl)-1-cyclopropyl-6fluoro-1, 4-dihydro-4-oxoquinoline-3-carboxylic acid. Zinc prolinate, a biocompatible catalyst was synthesized, characterized, and used in ring opening polymerization of L-lactide. Five different kinds of OH-terminated poly(L-lactide) (two-, three-, four-, six-arm, star-shaped) homopolymers were synthesized by ring opening polymerization of L-lactide in the presence of dodecanol, glycerol, pentaerythritol, dipentaerythritol as initiator and zinc prolinate as a catalyst. The structures of the polymers and conjugates were thoroughly characterized by means of gel permeation chromatography, matrix-assisted laser desorption/ionization - time of flight mass spectrometry, and nuclear magnetic resonance spectroscopy. PLA (molecular weight $=100,000)$ and ciprofloxacin conjugated PLA were used for fabrication of nonwoven nanofiber mat (diameter ranges; $150-400 \mathrm{~nm}$ ) having pore size $(62-102 \mathrm{~nm})$ using electrospinning. The microbiological assessment shows that the release of ciprofloxacin possesses antimicrobial activity. The drugrelease behavior of the mat was studied to reveal potential application as a drug delivery system. The result shows that the ciprofloxacin release rates of the PLA conjugate nonwoven nanofiber mat could be controlled by the drug loading content and the release medium. The development of a biodegradable ciprofloxacin system, based on nonwoven nanofiber mat, should be of great interest in drug delivery systems.
\end{abstract}

Keywords: zinc prolinate, ciprofloxacin conjugated polylactides, CP-PLA, electrospinning, nonwoven nanofibers, drug release, antibacterial activity, MDR

\section{Introduction}

Polylactide or poly(L-lactic acid) (PLA) has attracted tremendous attention in biomedical application, and it is one of the most promising biopolymers in therapeutic applications, such as in functioning as an active macromolecular pharmaceutical substance for tissue regeneration, auxiliary materials and excipients, in production of macromolecular prodrugs, polymeric drug delivery systems, therapeutic systems, etc. ${ }^{1-9}$ PLA is efficiently obtained in the presence of ionic initiators as well as coordinative and enzymatic catalysts. ${ }^{10-15}$

The solubility of the antibiotic ciprofloxacin depends on $\mathrm{pH}$ value and it is almost insoluble in water and alcohol. It shows highest solubility $(>40 \mathrm{mg} / \mathrm{mL})$ at $\mathrm{pH} 4-5$. This corresponds to the hydrochloride form of ciprofloxacin, if the $\mathrm{pH}$ value is adjusted with hydrochloric acid $(\mathrm{HCl})$. Ciprofloxacin is almost insoluble in the neutral $\mathrm{pH}$ range, while solubility increases with increasing $\mathrm{pH}$ value (approximately $30 \mathrm{mg} / \mathrm{mL}$ at $\mathrm{pH} 11$ ). The stability of the dry substance of ciprofloxacin is very high at room temperature. 
Solutions in dialysis fluid $(25 \mathrm{mg} / \mathrm{L})$ are stable even after 42 days when stored at $37^{\circ} \mathrm{C}$.

Earlier reports in the literature also reveal that the solubilization of ciprofloxacin drug or $\mathrm{HCl}$ adduct of ciprofloxacin in several solvents such as methanol, 2-propanol, etc, is difficult at $27^{\circ} \mathrm{C}$ and also at elevated temperature. ${ }^{16}$ Ciprofloxacin was generally used as an oral therapy for several years. A few reports are available where ciprofloxacin is incorporated in different polymer matrices and release studies have been carried out. ${ }^{17,18}$ No studies so far have addressed the possibility for the topical application of ciprofloxacin conjugated with biocompatible and biodegradable PLA (antibacterial nonwoven electrospun mat), particularly as a wound dressing material (bandage).

It was demonstrated in fluoroquinolones that chemical modification of the secondary amine in the piperazinyl ring results in an ester conjugate. ${ }^{16}$ The conjugate retains comparable activity to the parent fluoroquinone, without the need of intracellular cleavage and release of antibiotic. ${ }^{16}$

Citrate-conjugated ciprofloxacin showed lower affinity for $\mathrm{Fe}^{\mathrm{III}}$ than citrate itself since carbonyl oxygen donors in amides bind less strongly to hard $\mathrm{M}^{\mathrm{III}}$-cations than oxygen donors in carboxylates. ${ }^{19} \mathrm{~N}$-acetyl ciprofloxacin has been obtained through microbiological transformation of enrofloxacin using the fungus Mucor ramannianus. ${ }^{20} \mathrm{~A}$ polyester conjugate of ciprofloxacin has also been prepared through the acid functional group. ${ }^{21}$

Ciprofloxacin is reported as a broad spectrum antibiotic used to treat a wide variety of bacterial infections. ${ }^{22}$ The mechanism of action of this class of antibiotics is via inhibition of cytoplasmic DNA gyrase or topoisomerase IV, which are required for bacterial DNA replication, ${ }^{23}$ and bacterial resistance arises primarily by amino acid substitution within these target enzymes. A secondary resistance mechanism in Gram-negative bacteria involves decreasing permeability of the outer membrane by reduction in the expression of key outer membrane porins. Outer membrane protein $\mathrm{F}$ is important in the movement of fluoroquinolones into the cell, and reducing protein $\mathrm{F}$ levels results in reduced permeability, leading to lower intracellular concentrations of fluoroquinolones. ${ }^{23}$ However, no attention has been focused on topical application, particularly in biomedical applications such as wound dressing, or more specifically, on nanofiber nonwoven mat bandages.

The major problem is the solubility of ciprofloxacin; it is insoluble in both polar and nonpolar solvents at room temperature. ${ }^{24}$ The solution form of ciprofloxacin is required for nanofabrication using electrospinning.
Therefore, ciprofloxacin conjugated PLA was designed and synthesized to overcome the solubility problem, and the solution may be used for the fabrication of nonwoven nanofiber by electrospinning. ${ }^{25}$

Aligned biodegradable polymers (nanofibrous structure) have been used as potential scaffold vessel engineering. ${ }^{26}$ The fabrication of nonwoven nanofiber of drug conjugated polymer, with pores, has been explored and characterized using techniques such as environmental scanning electron microscopy, X-ray defraction, etc. ${ }^{25}$ The cytotoxic nature and the antimicrobial activity of nonwoven nanofiber have been evaluated by the in vitro, drug kinetic, agar plate method. ${ }^{27}$

Electrospinning is one of the most important methods for making ultrafine fibers with small diameters and large surface areas, which make them ideal in mimicking the natural extracellular matrix required for tissue engineering and promoting cell adhesion, migration, and proliferation. ${ }^{28}$

Nanofibers from various synthetic polymers have been electrospun, including proteins, poly(lactic-co-glycolic acid), etc. Electrospun membranes made of natural polymers, and with excellent biocompatible properties, are accepted well in biomedical applications. Recently, electrospun membranes were successfully used in tissue engineering and drug delivery as carriers for slow, controlled drug release and wound healing. ${ }^{28}$ The release of ciprofloxacin from a polymer matrix (implant of screw and microsphere) has been attempted. ${ }^{29-32}$

The ester carbonyl of aliphatic polyester may also help in binding to hard $\mathrm{M}^{\mathrm{III}}$-cations, in addition to carbonyl oxygen donors in amides, and ultimately inhibit bacterial proliferation. Drug conjugated nanofibers can also mitigate scarring and pain in patients because of their hydrolytic quality and the subsequent enzymatic degradation of PLA into carbon dioxide and water.

The wound dressing material available in the current market has drawbacks in that it limits drugs to the surface only, it prevents permeation of oxygen to the wound site, it interferes with the removal of exudates from the wound, and complete removal of the bandage is difficult. The new fabricated ciprofloxacin-conjugated PLA (PLA-CP) nonwoven nanofiber mats may represent a breakthrough in providing effective wound dressing materials for general wound infections that require a controlled drug delivery rate.

Therefore, the present work highlights a unique approach to address 1) synthesis biocompatible zinc prolinate catalyst, 2) ring opening polymerization of L-lactide using zinc prolinate catalyst to provide biocompatible, nontoxic PLA (various ranges of molecular weights), 3) preparation of ciprofloxacin 
through the secondary amine group of the piperazine ring, 4) drug-conjugated PLA through ester linkage, 5) fabrication of electrospun nonwoven nanofiber mats having fiber of nanodimension, 6) uniform nanoporous structure, 7) antibacterial activity and greatly enhance the ciprofloxacin release at three different $\mathrm{pHs}(7.4,7.0,5.9$, and 1$)$. Our study focused on these key challenges with ciprofloxacin as a delivery material.

\section{Materials and methods Materials}

L-lactide (Purac Biochem, Gorinchem, the Netherlands) was purified by recrystallization from dried ethyl acetate (over calcium hydride) before use and thoroughly dried for 24 hours under vacuum at $30^{\circ} \mathrm{C}$. Ciprofloxacin, L-proline, D-proline, and zinc acetate were supplied by Sigma-Aldrich, (St Louis, MO, USA). Zinc prolinate (L- and/or D-) was prepared from zinc acetate and L- and/or D-proline ${ }^{33}$ and dried to a constant weight before use. 1-dodecanol and glycerol were distilled under reduced pressure. Pentaerythritol was purified by sublimation under reduced pressure. All other chemicals and solvents were analytical-grade from SD Fine (Mumbai, India) and were used without further purification. Double-distilled water was used in all experiments.

\section{Polymer synthesis}

For the synthesis of $\mathrm{OH}$-terminated polylactide (OH-PLA), L-lactide $(0.225 \mathrm{~mol})$, and 1-dodecanol $(0.001 \mathrm{~mol})$ were added in a glass ampoule. Zinc prolinate (biocompatible) catalyst $(0.001 \mathrm{~mol})$ was added to a $20 \mathrm{~mL}$, thick-walled ampoule under nitrogen atmosphere and was sealed under vacuum. The ampoule was heated in a sand bath at $180^{\circ} \mathrm{C}$ for 5 hours, then allowed to cool and broken. The content was dissolved in dichloromethane $\left(\mathrm{CH}_{2} \mathrm{Cl}_{2}\right)(15 \mathrm{~mL})$ and precipitated from cold methanol $(30 \mathrm{~mL})$. The precipitation was repeated three times. The precipitated polymer was filtered and dried under a vacuum. For the synthesis of the star-shaped OH-PLAs, the polymerization was also carried out with zinc prolinate in the presence of glycerol or pentaerythritol.

\section{Synthesis of carboxyl-terminated polylactide (COOH-PLA)}

The OH-PLA, succinic anhydride, 4-dimethylaminopyridine, and triethylamine were dissolved in 1,4-dioxane and stirred overnight at room temperature. 1,4-dioxane was removed under vacuum and the residue was dissolved in chloroform $\left(\mathrm{CHCl}_{3}\right)$ and then washed with distilled water three times. After the $\mathrm{CHCl}_{3}$ layer was separated, it was dried over anhydrous magnesium sulfate and filtered. The polymer was precipitated by the polymer solution being poured into an excess of methanol, filtered, and dried under a vacuum.

\section{7-(4-(2-Chloroacetyl) piperazin- I-yl)- I-cyclopropyl-6-fluoro- I, 4-dihydro-4- oxoquinoline-3-carboxylic acid}

Ciprofloxacin $(3.0 \mathrm{~g}, 9 \mathrm{mmol})$ and triethylamine $(1.3 \mathrm{~mL}$, $9 \mathrm{mmol}$ ) were stirred in $40 \mathrm{~mL}$ of dry methylene chloride at $0^{\circ} \mathrm{C}$ for 15 minutes. Chloroacetyl chloride $(1.1 \mathrm{~mL}, 14 \mathrm{mmol})$ was added by dropper. After stirring at $0^{\circ} \mathrm{C}$ for 15 minutes and at room temperature for 1 hour, the mixture was filtered, and the resulting solids were washed with water and methylene chloride. The aqueous layer was extracted with $330 \mathrm{~mL}$ of $\mathrm{CH}_{2} \mathrm{Cl}_{2}$. The organic layers were collected, dried over magnesium sulfate, and concentrated. The remaining residue was purified by silica gel chromatography $\left(\mathrm{CH}_{2} \mathrm{Cl}_{2}-\right.$ methanol $\left.2 \%\right)$ to yield the desired product $(2.68 \mathrm{~g}, 73 \%)$ as a pale yellow solid, with a melting point $>260^{\circ} \mathrm{C}$.

\section{Synthesis of PLA-CP}

PLA-CP was prepared by a subsequent condensation of equivalent amounts of carboxyl-terminated PLA (telechelic PLA) with 7-(4-(2-chloroacetyl)piperazin-1yl)-1-cyclopropyl-6-fluoro-1,4-dihydro-4-oxoquinoline-3carboxylic acid (or $\mathrm{Cp} 1$ ) in chlorinated solvent to produce the corresponding conjugated PLA at yields ranging from $75 \%-80 \%$. Proton nuclear magnetic resonance ( ${ }^{1} \mathrm{H}$ NMR) of the conjugated PLA was recorded using a $400 \mathrm{mHz}$ NMR spectrometer (Bruker, Billerica, MA, USA) .

\section{'H NMR analysis}

For the ${ }^{1} \mathrm{H}$ NMR measurements, the samples were dissolved in chloroform-d in $5 \mathrm{~mm}$ diameter ${ }^{1} \mathrm{H}$ NMR tubes at room temperature, and the structure of the PLA was analyzed with a Bruker Avance (Bruker) at $200 \mathrm{MHz}$ and $400 \mathrm{MHz}$.

\section{Drug polymer characterization using 'H NMR 'H NMR characteristics of OH-PLAs 1OH-PLA. ${ }^{1} \mathrm{H}$ NMR $\left(\mathrm{CDCl}_{3}, \delta\right): 5.18\{\mathrm{nH}, \mathrm{q},[\mathrm{OCO}-(\mathrm{CH})$ $\mathrm{OCO}]\}, 4.38\{1 \mathrm{H}, \mathrm{q},[\mathrm{OCO}(\mathrm{CH}) \mathrm{OH}]\}, 4.17\left\{2 \mathrm{H}, \mathrm{t},\left[\mathrm{C}\left(\mathrm{CH}_{2}\right)\right.\right.$ $\mathrm{OCO}]\}, 1.59\left[3 \mathrm{nH}, \mathrm{d},\left(\mathrm{CH}_{3}\right)\right]$. \\ 3OH-PLA. ${ }^{1} \mathrm{H} \mathrm{NMR}\left(\mathrm{CDCl}_{3}, \delta\right): 5.18\{3 \mathrm{nH}, \mathrm{q},[\mathrm{OCO}(\mathrm{CH})$ $\mathrm{OCO}]\}, 4.38\{3 \mathrm{H}, \mathrm{q},[\mathrm{OCO}(\mathrm{CH}) \mathrm{OH}]\}, 4.25[5 \mathrm{H}, \mathrm{d},(\mathrm{CH}$ and $\left.\left.\mathrm{CH}_{2}\right)\right], 1.59\left[9 \mathrm{nH}, \mathrm{d},\left(\mathrm{CH}_{3}\right)\right]$.}


4OH-PLA. ${ }^{1} \mathrm{HNMR}\left(\mathrm{CDCl}_{3}, \delta\right): 5.18\{4 \mathrm{nH}, \mathrm{q},[\mathrm{OCO}(\mathrm{CH})$ $\mathrm{OCO}]\}, 4.38\{4 \mathrm{H}, \mathrm{q},[\mathrm{OCO}(\mathrm{CH}) \mathrm{OH}]\}, 4.17\left\{2 \mathrm{H}, \mathrm{s},\left[\mathrm{C}\left(\mathrm{CH}_{2}\right)\right.\right.$ $\mathrm{OCO}]\}, 1.59\left[3 \mathrm{nH}, \mathrm{d},\left(\mathrm{CH}_{3}\right)\right]$.

${ }^{13} \mathrm{CNMR}\left(\mathrm{CDCl}_{3}, \delta\right): 169(\mathrm{OCO}), 69[\mathrm{OCO}-(\mathrm{CH}) \mathrm{OCO}]$, 67[OCO- $(\mathrm{CH}) \mathrm{OH}], 21\left[\mathrm{CH}\left(\mathrm{CH}_{3}\right) \mathrm{OH}\right], 17\left(\mathrm{CH}_{3}\right)$.

\section{NMR characteristics of $\mathrm{COOH}-\mathrm{PLAs}$}

1COOH-PLA. ${ }^{1} \mathrm{H}$ NMR $\left(\mathrm{CDCl}_{3}, \delta\right): 5.18\{\mathrm{nH}, \mathrm{q},[\mathrm{OCO}(\mathrm{CH})$ $\mathrm{OCO}]\}, 2.68\left\{4 \mathrm{H}, \mathrm{t},\left[\mathrm{OCO}\left(\mathrm{CH}_{2} \mathrm{CH}_{2}\right)-\mathrm{COOH}\right]\right\}, 4.17\{2 \mathrm{H}, \mathrm{t}$, $\left.\left[\mathrm{C}\left(\mathrm{CH}_{2}\right) \mathrm{OCO}\right]\right\}, 1.59\left[3 \mathrm{nH}, \mathrm{d},\left(\mathrm{CH}_{3}\right)\right]$.

3COOH-PLA. ${ }^{1} \mathrm{H}$ NMR $\left(\mathrm{CDCl}_{3}, \delta\right): 5.18\{3 \mathrm{nH}, \mathrm{q}$, $[\mathrm{OCO}(\mathrm{CH}) \mathrm{OCO}]\}, 2.68\left\{12 \mathrm{H}, \mathrm{t},\left[\mathrm{OCO}\left(\mathrm{CH}_{2} \mathrm{CH}_{2}\right)-\mathrm{COOH}\right]\right\}$, $4.25\left[5 \mathrm{H}, \mathrm{d},\left(\mathrm{CH}\right.\right.$ and $\left.\left.\mathrm{CH}_{2}\right)\right], 1.59\left[9 \mathrm{nH}, \mathrm{d},\left(\mathrm{CH}_{3}\right)\right]$.

4COOH-PLA. ${ }^{1} \mathrm{H}$ NMR $\left(\mathrm{CDCl}_{3}, \delta\right): 5.18\{4 \mathrm{nH}, \mathrm{q}$, $[\mathrm{OCO}(\mathrm{CH}) \mathrm{OCO}]\}, 2.68\left\{16 \mathrm{H}, \mathrm{t},\left[\mathrm{OCO}\left(\mathrm{CH}_{2} \mathrm{CH}_{2}\right)-\mathrm{COOH}\right]\right\}$, $4.17\left\{2 \mathrm{H}, \mathrm{s},\left[\mathrm{C}\left(\mathrm{CH}_{2}\right) \mathrm{OCO}\right]\right\}, 1.59\left[3 \mathrm{nH}, \mathrm{d},\left(\mathrm{CH}_{3}\right)\right]$.

${ }^{13} \mathrm{C} \mathrm{NMR}\left(\mathrm{CDCl}_{3}, \delta\right): 169$ (OCO), 69 [OCO-(CH)OCO], $28\left[\mathrm{OCO}\left(\mathrm{CH}_{2} \mathrm{CH}_{2}\right) \mathrm{COOH}\right], 21\left[\mathrm{C}\left(\mathrm{CH}_{2}\right)-\mathrm{OCO}\right], 17\left(\mathrm{CH}_{3}\right)$.

\section{7-(4-(2-Chloroacetyl)piperazin-I-yl)-I-cyclopropyl-6-} fluoro-I,4-dihydro-4-oxoquinoline-3-carboxylic acid (CpI) ${ }^{1} \mathrm{H}$ NMR (DMSO-d $)$ d 1.19 (t, 2H, 3J=7.2 Hz, $\mathrm{CH}_{2}$ [12]), 1.32 (t, 2H, 3J=6.9 Hz, $\left.\mathrm{CH}_{2}[13]\right), 3.37$ (m, 4H, $\left.\mathrm{CH}_{2}[16]\right)$, $3.70\left(\mathrm{~m}, 4 \mathrm{H}, \mathrm{CH}_{2}[15]\right), 3.82(\mathrm{tt}, 1 \mathrm{H}, 3 \mathrm{~J}=7.2 \mathrm{~Hz}, 3 \mathrm{~J}=6.9 \mathrm{~Hz}$, $\mathrm{CH}[11]), 4.45$ (s, 2H, $\left.\mathrm{CH}_{2}-\mathrm{Cl}\right), 7.58$ (d, 1H, 4JH-F=7.6 Hz, $\mathrm{CH}$ [8]), 7.92 (d, 1H, 3JH-F=13.2 Hz, CH [5]), 8.66 (s, 1H, $\mathrm{CH}[2]), 14.7$ (s, $1 \mathrm{H},-\mathrm{COOH}) .{ }^{13} \mathrm{C}$ NMR (DMSO-d 6 ) d 176.2 (d, 4JC-F=2.6 Hz, C4), 165.7 (C14), 166.7 (C17), 152.8 (d, 1JC-F=249.3 Hz, C6), 147.9(C2), 144.6 (d, 2JC-F=10.2 Hz, C7), 138.9 (C9), 118.7 (d, 3JC-F=7.7 Hz, C10), 110.8 (d, 2JC-F=23.1 Hz, C5), 106.6 (C3), 106.4(d, 3JC-F=3.1 Hz, C8), 49.3 (C15), 48.9 (C15), 44.8 (C16), 41.6 (CH2-Cl), 41.2 (C16), 35.8 (C11), 7.4 (C12, 13). Fast atom bombardment mass spectroscopy (FAB-MS) m/z 408 [MH+]. Analytically calculated for $\mathrm{C}_{19} \mathrm{H}_{19} \mathrm{ClFN}_{3} \mathrm{O}_{4} \cdot 0.4 \mathrm{H}_{2} \mathrm{O}: \mathrm{C}, 54.99 ; \mathrm{H}, 4.81 ; \mathrm{N}$, 10.12. Found: C, 54.90; H, 4.65; N, 10.15 .

${ }^{1} \mathrm{H} \mathrm{NMR}\left(\mathrm{DMSO}_{\mathrm{f}}\right.$ ) d 1.23 (t, 2H, 3J=7.2 Hz, $\left.\mathrm{CH}_{2}[12]\right)$, 1.23 (t, 2H, 3J=6.9 Hz, CH $\mathrm{CH}_{2}$ [13]), 3.33 (m, 4H, $\left.\mathrm{CH}_{2}[16]\right)$, $3.70\left(\mathrm{~m}, 4 \mathrm{H}, \mathrm{CH}_{2}[15]\right), 3.83(\mathrm{tt}, 1 \mathrm{H}, 3 \mathrm{~J}=7.2 \mathrm{~Hz}, 3 \mathrm{~J}=6.9 \mathrm{~Hz}$, $\mathrm{CH}[11]), 4.45$ (s, 2H, $\left.\mathrm{CH}_{2}-\mathrm{Cl}\right), 7.60$ (d, 1H, 4JH-F=7.6 Hz, $\mathrm{CH}(8)), 7.95$ (d, 1H, 3JH-F=13.2 Hz, CH [5]), 8.31 (s, 1H, $\mathrm{CH}[2]), 14.7$ (s, 1H, - $\mathrm{COOH})$.

\section{Molecular weights}

The molecular weights (number-average molecular weight [Mn], weight-average molecular weight $[\mathrm{Mw}]$, and polydispersity $[\mathrm{Mw} / \mathrm{Mn}]$ ) were determined with respect to polystyrene standards by size-exclusion chromatography on an
Agilent Technologies Polymer Laboratories -Gel permeation chromatography (PL-GPC) 220 machine (Santa Clara, CA, USA) at $25^{\circ} \mathrm{C}$, with eluting PLA solutions $(10 \mathrm{mg} / \mathrm{mL}$ of $\mathrm{CHCl}_{3}$ ) and toluene as an internal standard, and through a series of five $30 \mathrm{~cm}$ long Styragel columns (Waters Corporation, Milford, MA, USA) with pore sizes of 500, 105, 104, 103 , and $100 \AA . \mathrm{CHCl}_{3}$ was used as the mobile phase (flow rate: $1 \mathrm{~mL} /$ minute), and a refractive-index detector was used for the detection of different molecular weight fractions.

\section{Matrix-assisted laser desorption/ ionization - time of flight mass spectrometry (MALDI-TOF MS) analysis}

MALDI-TOF MS analysis was performed on a Voyager-DE STR (Life Technologies, Carlsbad, CA, USA). The MALDITOF spectrometer is equipped with $2 \mathrm{~m}$ reflection flight tubes as well as a $337 \mathrm{~nm}$ nitrogen laser with a pulse width of 3 nanoseconds. All experiments were carried out at an accelerating potential of $20 \mathrm{kV}$. In general, mass spectra from 200 shots were accumulated to produce a final spectrum. The obtained data were smoothened to reduce the spikiness by the average method; the smoothening filter moved along the collected data channels, adding together a number of channels and dividing by that number to give an average signal. This smoothening, however, did not eliminate or hide minor signals distinct from the baseline noise. The samples were dissolved in tetrahydrofuran $(1 \mathrm{mg} / \mathrm{mL})$ and mixed with the matrix ( $15 \mathrm{mg} / \mathrm{mL}$ of tetrahydrofuran) before being dried on the sample plate. 2,5-Dihydroxybenzoic acid and dithranol were used as the matrix. The sample plate was inserted into the apparatus under a high vacuum $\left(\sim 10^{-5} \mathrm{~Pa}\right)$.

\section{Electrospinning of nonwoven nanofiber containing PLA-CP}

The homogeneous solution of PLA-CP and PLA (Mw $100,000)$ in $14 \%\left(\mathrm{CHCl}_{3} / \mathrm{N}, \mathrm{N}\right.$-dimethylformamide $)$ was electrospun at $23-27 \mathrm{kV}$, under a steady flow rate of 20 $\mu \mathrm{L} /$ minute using a spinneret with a diameter of $0.7 \mathrm{~mm}$. The electrospun nanofiber was collected on an aluminum foil. The distance between the spinneret and the collector was $15 \mathrm{~cm}$. The resulting nanofiber was vacuum dried at room temperature for a week to completely remove any solvent residue prior to the experiments. Thermogravimetry analysis were performed to determine if there was any residual solvent in vacuum dried electrospun nanofibers, which showed no sign of residual solvent present in the samples. 


\section{Scanning electron microscope analysis}

The morphology of the PLA and PLA-CP nanofibers was studied with a Leica Cambridge Stereo scan Model 440 scanning electron microscope (SEM) (Leica Microsystems, Wetzlar, Germany).

\section{Antibacterial activity}

The antibacterial activities of nonwoven nanofiber were tested against Staphylococcus aureus (S. aureus) (National Collection of Industrial Microorganisms No 2122 [National Chemical Laboratory, Pune-8, Maharashtra, India]).

S. aureus was maintained on nutrient agar (beef extract $0.3 \%$, peptone $0.5 \%$, sodium chloride $0.5 \%$ ) slants and was inoculated into nutrient agar broth for 24 hours. Ciprofloxacin solution was used as a positive control.

\section{Minimum inhibitory concentration (MIC) determination}

In vitro antibacterial activity of PLA-CP nonwoven nanomat was studied against $S$. aureus to determine MIC. The experiments were carried out in triplicate, under similar experimental conditions. The MIC of ciprofloxacin was determined according to the standard broth microdilution technique as per the National Committee for Clinical Laboratory Standards (NCCLS) guidelines. ${ }^{23}$ Tests were performed in U bottom 36-well tissue culture plates in yeast extract, peptone, glucose nutrient agar for bacterial strain. The concentration range of ciprofloxacin in the nanomat and standard was $0.1-1.0 \mu \mathrm{g} / \mathrm{mL}$. The plates were incubated at $37^{\circ} \mathrm{C}$ for 24 hours, and MIC was determined at 99\% inhibition of growth, with respect to the growth control.

\section{Sample preparation}

A $(1 \times 1) \mathrm{cm}^{2}$ portion of nanofiber mat was used to study the antibacterial activity. All samples were sterilized under ultraviolet light, laminar flow before testing bacterial cultures. ${ }^{27,34}$

Bacterial cultures were observed, and Luria broth tubes (Sigma-Aldrich) containing the cultures were collected after 24 hours. Turbidity confirmed the growth of bacteria.

\section{Suspension method procedure}

Preparation of samples treated with bacterial culture

The dilutions for this study were in the range of $10^{-4}-10^{-6}$ in triplicate, and $1 \mathrm{~mL}$ from each stock solution was poured into the next solution tube and labeled it as ( $S$ aureus $10^{-4}$ dilution, colony forming units (CFUs) (150, Sample A)). The sterile sample was transferred using sterilized forceps, and was dipped in a labeled saline tube in laminar only. All sample tubes were sealed with cotton plugs and left for 24 hours in a $37^{\circ} \mathrm{C}$ incubator shaker set at a speed of $250 \mathrm{rpm}$. Saline tubes containing samples were collected, and $0.1 \mathrm{~mL}$ of solution was spread on each petri dish. Plates were incubated at $37^{\circ} \mathrm{C}$ for 24 hours, and on the next day, CFUs were counted. Appropriate control plates were processed similarly. Initial CFU counts were determined as reading as $150 \times 10^{-4}$.

\section{Calculation of percent inhibition of bacterial growth}

The percent inhibition of bacterial growth is calculated as,

$$
\begin{aligned}
& \text { Percentage of inhibition } \\
& =\frac{\text { initial count }- \text { final count }}{\text { initial count }} \times 100
\end{aligned}
$$

Phosphate buffered saline (PBS) is the typical medium used to mimic the fluid of a normal wound in drug release studies. Four kinds of release media (PBS at $\mathrm{pH}=7.0$ and $\mathrm{pH}=7.4$ and $\mathrm{HCl}$ aqueous solution at $\mathrm{pH}=5.9$ and $\mathrm{pH}=1.0$ ) were used to study in vitro release. Experiments to look at the release of ciprofloxacin from the polymer nonwoven nanomat were performed in triplicate, using $10 \mathrm{~mL}$ of buffer solution at different pHs. We suspended $150 \mathrm{mg}$ of nanofiber in 3.5 $\mathrm{mL}$ PBS in dialysis tubing (Spectra/Por 1 membrane, 6-8 kDa cut-off; SpectrumLabs, Rancho Dominguez, CA, USA). Dialysis tubing was placed in a screw-capped tube containing $10 \mathrm{~mL}$ of PBS. The tubes were shaken at $70 \mathrm{rpm}$ on a horizontal water bath shaker (Thermo Electron 480 Forma incubator orbital shaker; Thermo Fisher Scientific, Waltham, MA, USA) maintained at $37^{\circ} \mathrm{C} \pm 0.5^{\circ} \mathrm{C}$. At predetermined time intervals, the entire medium in the tube was withdrawn and replaced by fresh medium to maintain sink conditions. The aliquots were assayed by spectrophotometer at $262 \mathrm{~nm}$ to determine the concentration of ciprofloxacin released. The cumulative amount of ciprofloxacin released from the samples was calculated using the equation,

$$
\text { Cumulative drug released (\%) }=M_{t} / M_{\text {total }} \times 100
$$

where $M_{t}$ is the amount of ciprofloxacin released from the PLA-CP nanomat at time $t$, and $M_{\text {total }}$ is the total amount of ciprofloxacin loaded in the PLA nanomat.

\section{Results and discussion}

Wound dressing materials that contain antibiotics are impregnated systems that rely on simple diffusion of the antibiotic, either from the bulk of the polymer or directly from the surface after cleavage of ester bonds. The conjugated 
antimicrobial drug-polymer was synthesized; zinc proline was synthesized, characterized, and used as a biocompatible catalyst for the preparation of PLA. We have achieved the molecular weight of PLA more than 100,000 without any racemization. PLA-CP was also prepared. PLA and PLA$C P$ were subsequently used for fabrication of nonwoven nanofibers, and the synthesis of PLA-CP was carried out using a few synthetic steps. At the outset, OH-PLA was synthesized by the ring opening polymerization of L-lactide, using zinc prolinate as a catalyst in the presence of various alcohols, using the break seal technique. Zinc prolinate was prepared from zinc acetate, D-proline characterized and confirmed the structure. All polymerizations were conducted in a solventfree process with continuous stirring. Under these conditions, maximum homogeneous conversions were achieved after relatively short reaction times. 1-Dodecanol was used as initiator for making linear PLA as shown in Figure 1.

The structures hydroxyl- and carboxyl-terminated PLA, as shown in Figure 1, were confirmed by ${ }^{1} \mathrm{H}$ and carbon-13 NMR spectroscopy. The chemical structures of Cp1 and PLA$\mathrm{CP}$ were confirmed by ${ }^{1} \mathrm{H}$ NMR as shown in Figures 2-4.

Three-arm PLA and four-arm PLA were synthesized with glycerol and pentaerythritol as the respective initiators. ${ }^{1} \mathrm{H}$ NMR spectra showed that the methyl and methine proton resonance of the lactate units appeared at $\delta 1.59$ and $5.18 \mathrm{ppm}$. The pentaerythritol methylene protons exhibited two peaks; the one attached to lactate is observed at $\delta 4.17$ and one unreacted pentaerythritol is observed at $\delta 3.5 \mathrm{ppm}$.

\section{Molecular weight}

The Mw (polystyrene equivalent) of PLA was determined to be $1.08 \times 10^{6}$ with a polydispersity of 1.6 . The dry polymer was white in color, and the yield for the polymer was $98 \%$. Gel permeation chromatography results show that all polymers display monodisperse curves and no dual peaks.
The Mn and Mw of linear PLA oligomers are 5,000 and 8,000 Da, respectively. The Mn and Mw of three-arm PLA oligomers are 10,000 and 17,000 Da, respectively. The Mn and Mw of star-shaped, four-arm PLA oligomers are 19,000 and 27,200 Da, respectively. The star-shaped structure of PLA oligomers was deduced from the integration ratios of the pentaerythritol methylene proton peak and the terminal methine peak, which are about $2 / 1$. For three-arm PLA, it was about $5 / 3$. Similar observations have been made in the literature. $^{13}$

\section{NMR analysis}

COOH-PLA was synthesized through the ring opening reaction of the hydroxyl-terminated PLA with succinic anhydride (Figure 1). 4-Dimethylaminopyridine and triethylamine were used as catalyst, and 1, 4-dioxane was used as solvent. The reaction was allowed to proceed efficiently because of activation of the succinic anhydride, and good yields of COOH-PLA were obtained. ${ }^{1} \mathrm{HNMR}$ spectra showed the methine proton at $\delta 4.35$ at chain terminus disappeared, and the methylene proton formed by the ring opening reaction of succinic anhydride was located at $\delta 2.68$. Also, the methylene carbon from succinic anhydride appeared at $\delta 2.7$. The structure of $\mathrm{COOH}-\mathrm{PLA}$ was identified by the calculation of the ratio of integrated peak areas of the methylene protons of the pentaerythritol and the methylene protons of the polymer chain ends. For 4COOH-PLA, the ratio was $1 / 2$ which has already been reported in the literature. ${ }^{13}$

Starting from commercially available ciprofloxacin, Cp1 was easily prepared in one step. Acylation of ciprofloxacin with chloroacetyl chloride led to $\mathrm{Cp} 1$ yields of $75 \%$ after purification. The ${ }^{1} \mathrm{H}$ NMR measurements demonstrated excellent conversion and purity of compound $\mathrm{Cp} 1$ as shown in Figure 2, and peak assignments are shown in the experimental section.

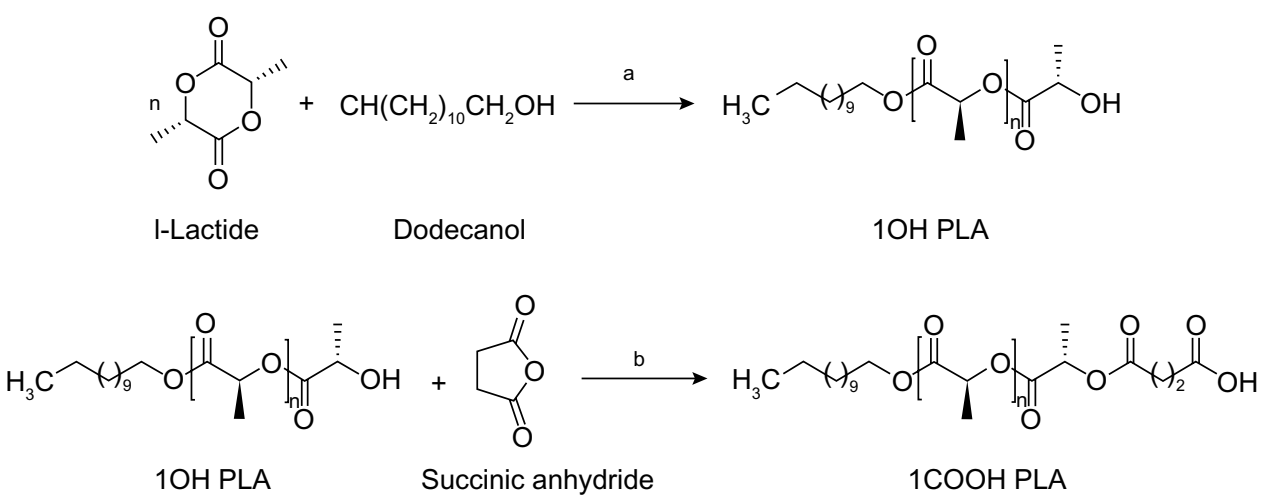

Figure I Synthesis route for end functional PLA showing a) zinc proline at $180^{\circ} \mathrm{C}$, b) succinic anhydride, TEA, DMAP at room temperature. Abbreviations: COOH-PLA, carboxyl-terminated PLA; DMAP, 4-dimethylaminopyridine; OH-PLA, OH-terminated polylactide; PLA, polylactide; TEA, triethylamine. 


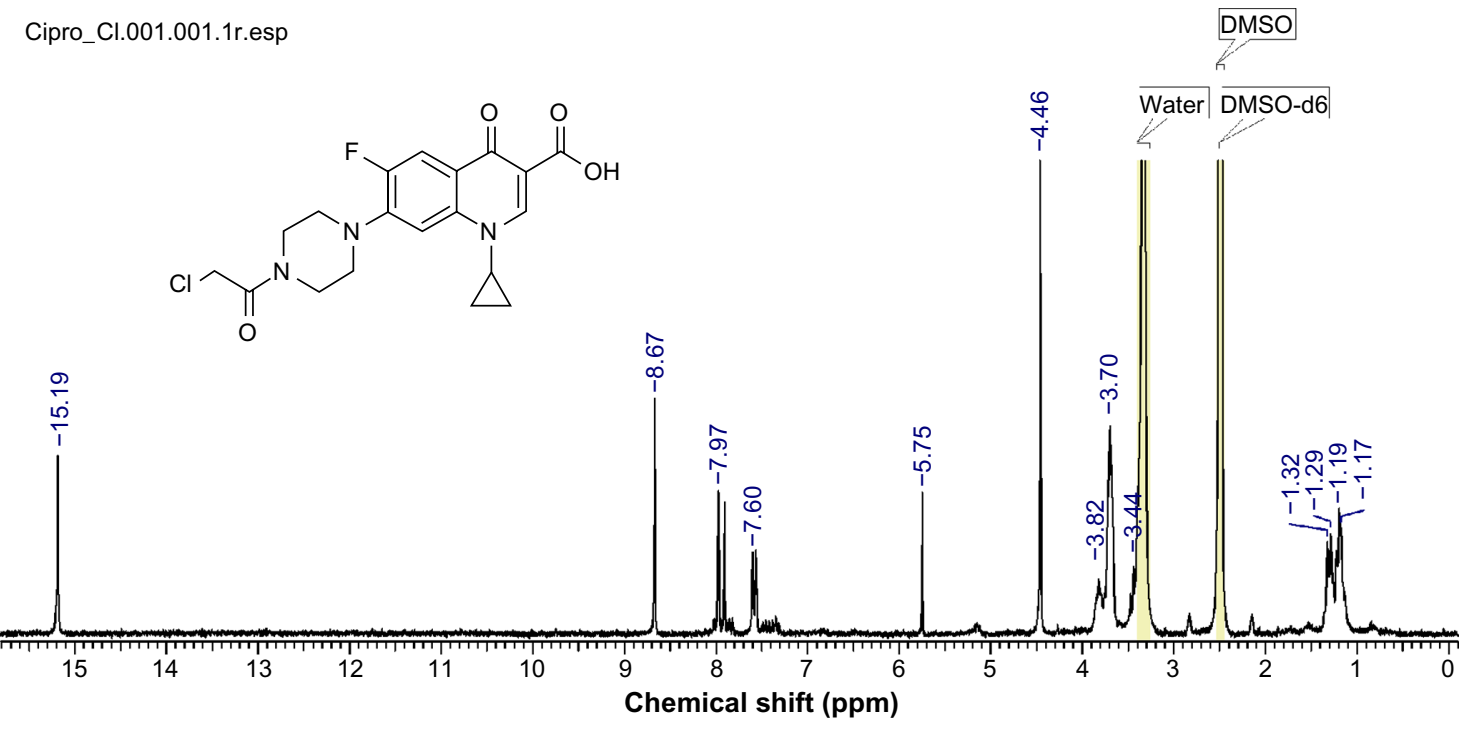

Figure 2 'H NMR measurement of 7-(4-(2-chloroacetyl) piperazin- I-yl)- I-cyclopropyl-6-fluoro-I, 4-dihydro-4-oxoquinoline-3-carboxylic acid. Abbreviations: DSMO, dimethyl sulfoxide; 'H NMR, proton nuclear magnetic resonance.

The homologous series of PLA-CP were prepared by a subsequent condensation of carboxyl-terminated PLA with $\mathrm{Cp} 1$ in chlorinated solvent to produce the corresponding conjugates with yield of $\sim 75 \%$ (path a in Figure 4 ).

The structure and purity of the PLA-CP were determined by ${ }^{1} \mathrm{H}$ NMR as shown in Figure 3; peak assignments are marked in the spectra and also shown in the experimental section.

\section{MALDITOF}

MALDI-TOF MS was employed for the determination of molecular weights and the nature of end groups. ${ }^{35,36}$
PLA-CP was prepared by condensation reaction and subjected to MALDI-TOF MS analysis. Figure 5A-C show the MALDI-TOF MS for the hydroxyl-, carboxyl- and ciprofloxacin-terminated PLA.

The most prominent series of peaks is characterized by a mass increment of $72 \mathrm{Da}$, which is equal to the mass of the repeating unit in the PLA polymer (Figure 5A-C). Figure 5A shows a typical MALDI-TOF spectrum of sample OH-PLA. This series is assigned to PLA oligomers terminated with a hydroxyl group at one end and dodecyl group on the other. The MALDI spectrum is determined by a series of intense

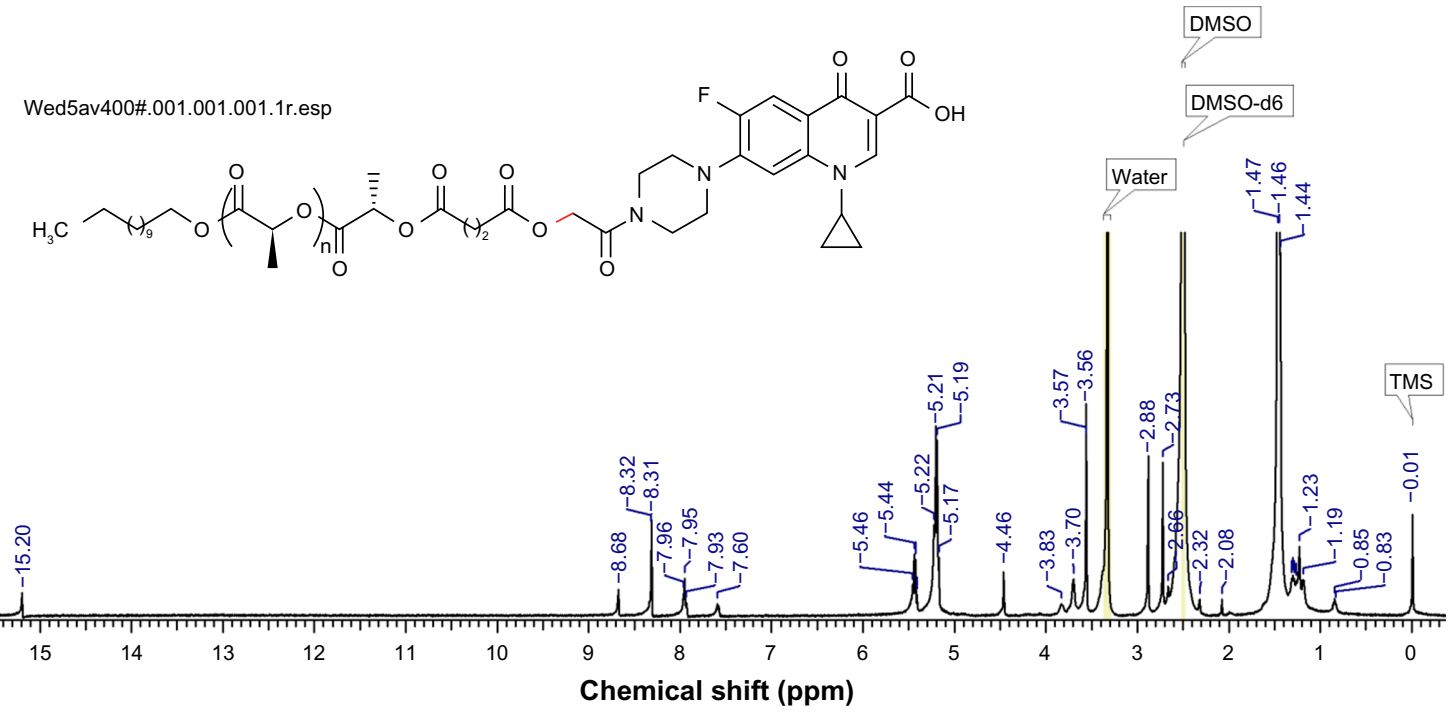

Figure 3 'H NMR measurement of ciprofloxacin-conjugated PLA in DMSO-d.

Note: The red bond indicates the new conjugation bond formation between PLA and CpI.

Abbreviations: CpI, 7-(4-(2-chloroacetyl) piperazin-I-yl)-I-cyclopropyl-6-fluoro-I, 4-dihydro-4-oxoquinoline-3-carboxylic acid; DSMO, dimethyl sulfoxide; 'H NMR, proton nuclear magnetic resonance; PLA, polylactide; TMS, chloromethyl trimethylsilane. 
<smiles>O=C(O)c1cn(C2CC2)c2cc(N3CCN(C(=O)CCl)CC3)c(F)cc2c1=O</smiles>

$\mathrm{Cp}$

Cp1

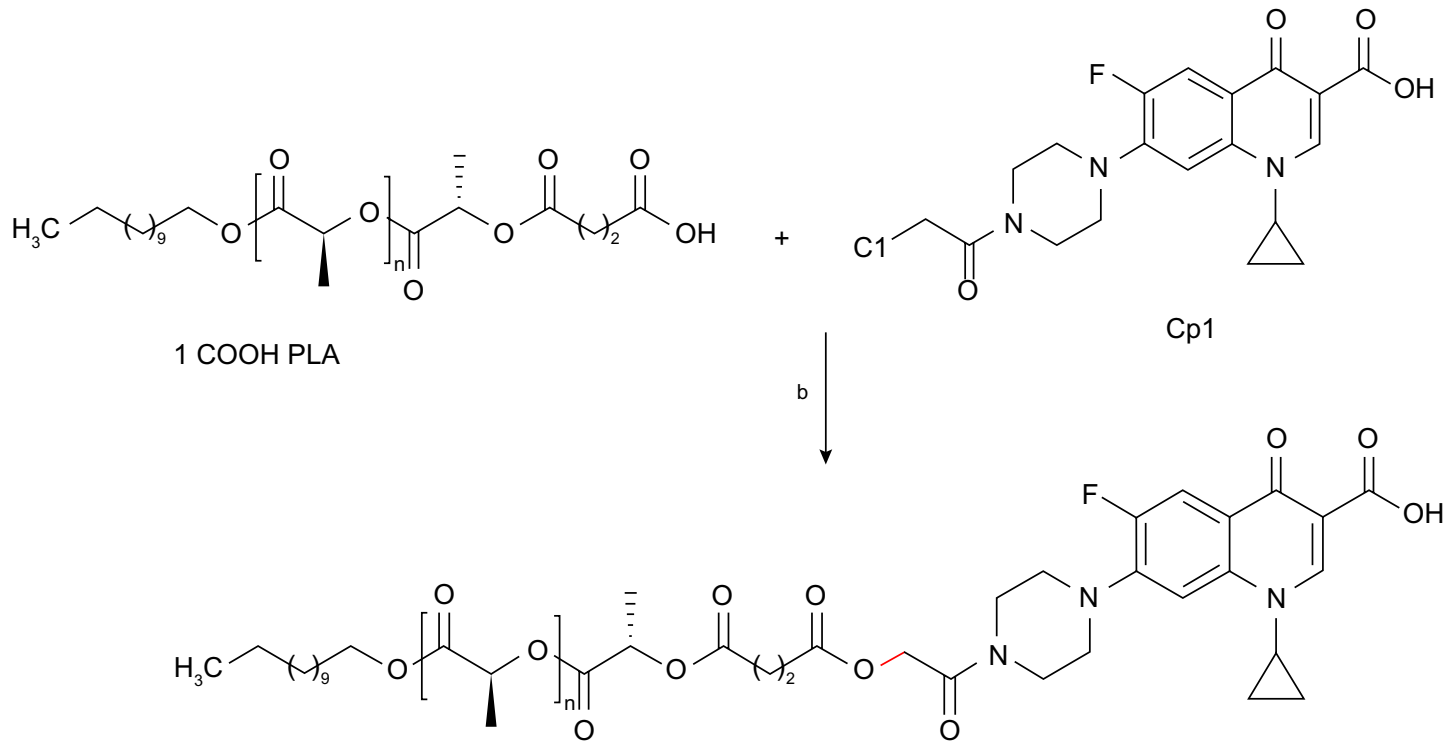

\section{Ciprofloxacin-PLA conjugate}

Figure 4 Synthesis of ciprofloxacin derivative and conjugation with end functional PLA a) TEA, $\left.\mathrm{ClCH}_{2} \mathrm{COCl}_{2} \mathrm{CH}_{2} \mathrm{Cl}_{2}, 0^{\circ} \mathrm{C}-\mathrm{room} \mathrm{temperature;} b\right) \mathrm{K}_{2} \mathrm{CO}$, DMF, I00 ${ }^{\circ} \mathrm{C}$. Abbreviations: $C_{p}$, ciprofloxacin; Cpl, 7-(4-(2-chloroacetyl) piperazin-I-yl)-I-cyclopropyl-6-fluoro-I, 4-dihydro-4-oxoquinoline-3-carboxylic acid; COOH-PLA, carboxylterminated PLA; DMF, N,N-dimethylformamide; PLA, polylactide; TEA, triethylamine.

peaks ranging from a mass of 1,124 Da to a mass of 4,007 $\mathrm{Da}$, corresponding to oligomers doped with hydrogen $\left(\mathrm{H}^{+}\right)$ions of type $\mathrm{CH}_{3}-\left(\mathrm{CH}_{2}\right)_{11}-\left(\mathrm{O}-\mathrm{CO}-\mathrm{CH}-\mathrm{CH}_{3}\right)_{\mathrm{n}}-\mathrm{OH}-\mathrm{H}^{+}$ (mass $=72 \mathrm{n}+58+1)$; $\mathrm{n}$ values varying from 15 to 55 were detected, 1 being the mass number of one proton. The peaks belong to the series 1,260 $\mathrm{Da}$; 4,245 $\mathrm{Da}$ corresponding to oligomers with $n$ values of $17-58$, are labeled in the spectrum and reported as enlarged in the inset. These peaks correspond to PLA oligomers doped with sodium ions of type $\mathrm{CH}_{3}-$ $\left(\mathrm{CH}_{2}\right)_{11}-\left(\mathrm{O}-\mathrm{CO}-\mathrm{CH}-\mathrm{CH}_{3}\right) \mathrm{OH}-\mathrm{Na}^{+}($mass $=72 \mathrm{n}+42+23)$. The spectrum also displays other peaks of lower intensity, which disrobed as oligomers doped with potassium $\left(\mathrm{K}^{+}\right)$ions $\left(\mathrm{K}^{+}\right.$ adduct molecular ions, mass $=72 \mathrm{n}+42+39$; see the peak at 1,$381 ; 1,527 ; 1,544 ; 1,813 ; 1,957 ; 2,028 ; 2,534 ; 4,116$; and 4,259 in the inset).

Similarly, the oligomer contained chains terminated by a carboxyl group on one side and dodecyl group on the other as shown in Figure 5B. The MALDI spectrum is dominated by a series of intense peaks, ranging from a mass of 1,366 to $1,798 \mathrm{Da}$, corresponding to oligomers doped with $\mathrm{H}^{+}$ions of type $\mathrm{CH}_{3}\left(\mathrm{CH}_{2}\right)_{11}-(\mathrm{O}-\mathrm{CO}-$ $\left.\mathrm{CHCH}_{3}\right)_{\mathrm{n}}-\mathrm{O}-\mathrm{COCH}_{2} \mathrm{CH}_{2}-\mathrm{COOH}-\mathrm{H}^{+}($mass $=72 \mathrm{n}+70+1)$; $\mathrm{n}$ values varying from 18 to 24 were detected, 1 being the mass number. The other series of peaks ranging from a mass of 1,535 Da to a mass of 3,192 Da, corresponding to oligomers doped with sodium ions of type $\mathrm{CH}\left(\mathrm{CH}_{2}\right)_{11}-(\mathrm{O}-$ $\left.\mathrm{CO}-\mathrm{CHCH}_{3}\right)_{\mathrm{n}}-\mathrm{COOH}-\mathrm{Na}^{+}$( mass $\left.=72 \mathrm{n}+70+23\right)$, $\mathrm{n}$ values varying from 21 to 41 were detected, 23 being the mass number of sodium. The few intense peaks belonging to this series, corresponding to oligomers with n values 17 to 41 , are labeled in the spectrum and reported as enlarged in the inset.

Figure 5C shows the MALDI spectrum of PLA-CP polymers. The most intense peaks belonging to this series, corresponding to oligomers with $n$ values of 20 to 50 , are labeled in the spectrum and reported as enlarged in the inset. The peaks ranging from 1,465 Da to 3,556 Da correspond to oligomers doped with $\mathrm{K}^{+}$ions of type $\mathrm{CH}_{3}-\left(\mathrm{CH}_{2}\right)_{11}-\left(\mathrm{O}-\mathrm{CO}-\mathrm{CHCH}_{3}\right)$ 

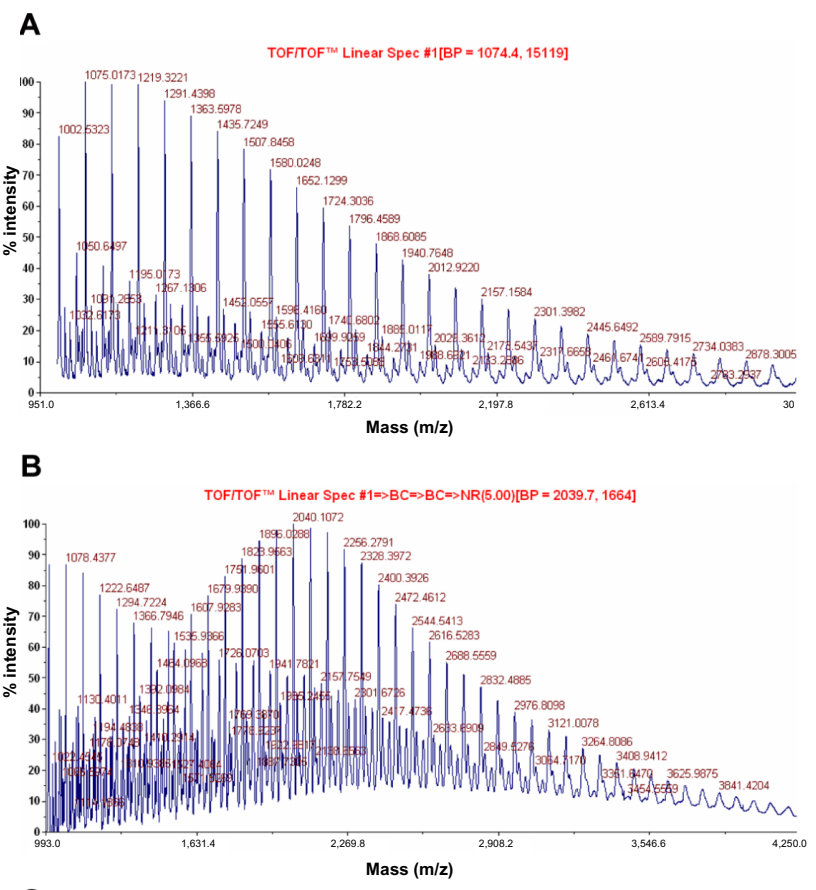

C

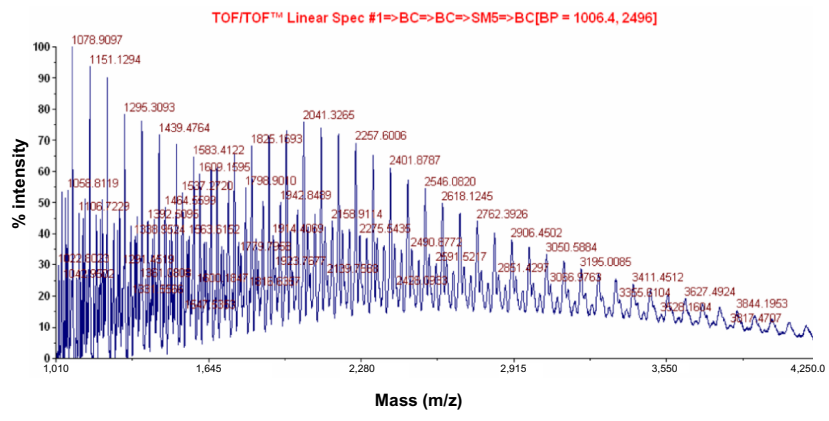

Figure 5 MALDI-TOF MS for the hydroxyl-, carboxyl- and ciprofloxacin-terminated PLA.

Notes: MALDI-TOF/TOF spectra of hydroxyl-terminated PLA (IOH-PLA) (A); MALDI-TOF/TOF spectra of carboxyl-terminated PLA (ICOOH-PLA) (B); and MALDI-TOF/TOF spectra of ciprofloxacin conjugated PLA (PLA-CP) (C).

Abbreviations: MALDI-TOF MS, matrix-assisted laser desorption/ionization-time of flight mass spectrometry; PLA, polylactide.

n-O-CO- $\mathrm{CH}_{2} \mathrm{CH}_{2}-\mathrm{CO}-\mathrm{CP}-\mathrm{Na}^{+}$(mass $\left.=72 \mathrm{n}+58+39\right)$. The spectrum displays another series of peaks ranging from 1,295 to 2,663 Da, corresponding to oligomers doped with $\mathrm{H}^{+}$of type $\mathrm{CH}_{3}-\left(\mathrm{CH}_{2}\right)_{11}-\left(\mathrm{O}-\mathrm{CO}-\mathrm{CHCH}_{3}\right)_{n}-\mathrm{O}-\mathrm{CO}-\mathrm{CH}_{2} \mathrm{CH}_{2}-$ $\mathrm{CO}-\mathrm{OH}-\mathrm{H}^{+}$(mass $\left.=72 \mathrm{n}+70+1\right)$; $\mathrm{n}$ values varying from 17 to 36 were detected, 1 being the mass number of sodium. The spectrum also displays other peaks of lower intensity, which desorbed as oligomers doped with $\mathrm{K}^{+}$ions $\left(\mathrm{K}^{+}\right.$adduct molecular ions, mass $=72 n+58+39$; see the peaks ranging from 2,413 to 2,939). The MALDI-TOF result showed that the PLA-CP binds to the ciprofloxacin moiety like the hydrochloride salt of ciprofloxacin. The spectra confirmed the presence of hydroxyl, carboxyl, and ciprofloxacin end groups in PLA.
The high molecular weight PLA ( $\mathrm{Mw}=100,000$, prepared in our laboratory using biocompatible zinc prolinate) and PLA-CP were uniformly mixed in a common solvent and nanofiber mats were prepared by an electrospinning method in order to mimic the nanofibrous structure of extracellular matrixes of tissues in the body. Although various methods have been reported to produce porous polymer scaffolds for tissue engineering applications, nanofibers have also attracted much attention for their tissue regeneration and wound healing applications. ${ }^{37}$

\section{SEM}

Figure 6A-C shows the images of PLA (L and D form), 0.003 mol PLA-CP, and 0.015 mol PLA-CP nanofibers. Figure 6D shows the image of $0.015 \mathrm{~mol}$ PLA-CP nanofibers after 1 hour heat treatment. The strength of the nanofibers was enhanced after heat treatment at $150^{\circ} \mathrm{C}$, without reducing the activity of ciprofloxacin, and in fact, it became stabilized due to drug conjugation. Figure 7 shows nonporous morphology in a single PLA nanofiber. PLA-CP nanofibers (before and after heat treatment for 1 hour) ranged in diameter from 210-350 $\mathrm{nm}$ with a unimodal size distribution (Figure 6A-D).

Figure 6D shows the SEM image of PLA-CP $(0.015 \mathrm{~mol}$ of ciprofloxacin) nanofibers after 1 hour heat treatment at $150^{\circ} \mathrm{C}$, and the surface morphology remains intact. Figure 7 shows the SEM image of PLA-CP ( $0.015 \mathrm{~mol}$ ciprofloxacin $)$ nanopores varying from $65-102 \mathrm{~nm}$, allowing for the diffusion of oxygen to the wound site and removal of exudates from the wound.

\section{Drug release}

Figure 8 shows the area of inhibition (\%) of $S$. aureus versus PLA-CP mat with different concentrations of ciprofloxacin.

\section{Antimicrobial activity of PLA-CP nonwoven nanofiber mats}

To evaluate the antibacterial activity of the selected drugcontaining nanofiber and pure ciprofloxacin samples, the agar diffusion method and broth dilution method were used. These are highly reliable methods for testing antibacterial agents against organisms like $S$. aureus. These tests were performed according to the NCCLS guideline. ${ }^{23}$ Mean inhibitory diameters related to each of the PLA-CP nonwoven nanofiber mats were compared to their pure drug counterparts in the same concentrations, using oneway analysis of variance (ANOVA). $P$-values $<0.01$ were considered significant. 

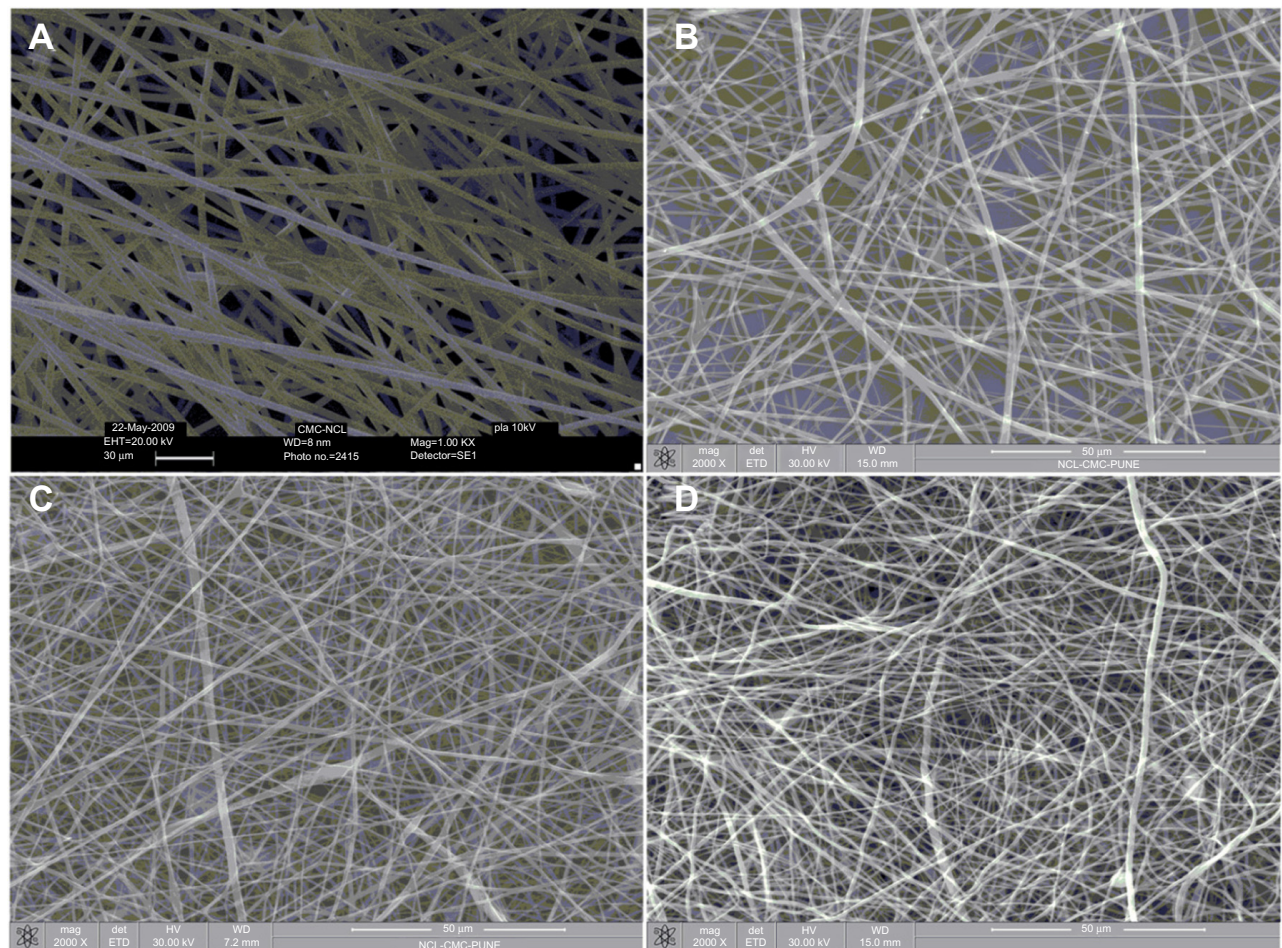

Figure 6 SEM images of PLA nanofibers (A), PLA-CP (0.003 mol) nanofibers (B), PLA-CP (0.0I5 mol) nanofibers (C), and PLA-CP nanofiber after I hour heat treatment (D). Abbreviations: CpI, 7-(4-(2-chloroacetyl) piperazin-I-yl)-I-cyclopropyl-6-fluoro-I, 4-dihydro-4-oxoquinoline-3-carboxylic acid; PLA, polylactide; PLA-CP, ciprofloxacinconjugated PLA; SEM, scanning electron microscopy.

In this study, in order to provide useful information with regard to biological functions, antibacterial performances of PLA and drug-conjugated PLA nanofibers were evaluated against $S$. aureus and are shown in Figure 9A and B.

A clear zone of inhibition within the PLA nonwoven nanofiber mat could be seen after 24 hours of incubation of the agar plate at $37^{\circ} \mathrm{C}$. The antibacterial activity of the drug-conjugated nanofibers was assessed by measuring the diameter of an inhibition ring. The zone diameters obtained

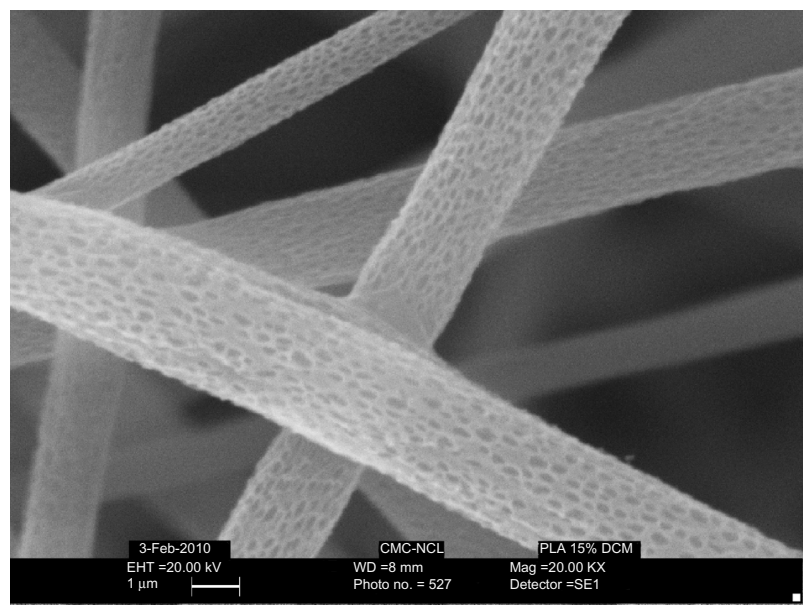

Figure 7 SEM images of PLA nanofibers with nano pores.

Abbreviations: PLA, polylactide; SEM, scanning electron microscopy. for these drug-conjugated nanofibers imply that the bacterial colony was susceptible to ciprofloxacin released from the nanofiber mat. In the case of drug-conjugated nanofibers, the drug molecules could freely diffuse into the test media and act as biocidal agents. In addition, the nanometersized drug conjugated polymer nanofiber provides a large surface area to contact with bacteria. A $31.9 \mathrm{~mm}$ diameter zone was observed in the case of $S$. aureus. The MIC for S. aureus was $0.55 \mu \mathrm{g} / \mathrm{mL}$. For instance, the concentration of $4.40 \mu \mathrm{g} / \mathrm{mL}$ of pure ciprofloxacin in Figure 9B produced a mean inhibitory diameter of $30.3 \mathrm{~mm}$, whereas drug-containing electrospun nonwoven nanomat (Figure 9C) shows the comparable inhibitory diameter $(31.9 \mathrm{~mm})$ in the concentration of $0.55 \mu \mathrm{g} / \mathrm{mL}$, indicating eight times reduction in the ciprofloxacin concentration to achieve the same antibacterial activity against $S$. aureus. Blank PLA nanofiber mat indicated no antibacterial activity against $S$. aureus.

Figure 9C shows a zone diameter of $28.6 \mathrm{~mm}$, which was recognized in the case of Gram-negative bacteria Escherichia coli (E. coli). The MIC for E. coli was $1.15 \mu \mathrm{g} / \mathrm{mL}$. When the incubation times were varied from 24 to 48 hours, the inhibition zones remained unaffected in the case of E. coli, as shown in Table 1.

Figure 10 shows the SEM images of PLA and PLA-CP nanofiber mats with bacteria. The micrograph shows bacterial 


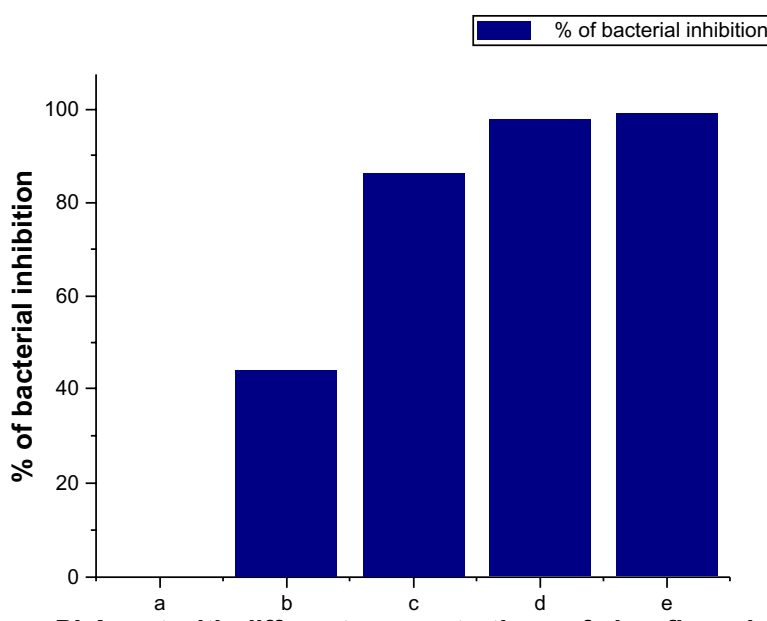

PLA mat with different concentrations of ciprofloxacin

Figure 8 Antibacterial effect of nonwoven nanomats containing different concentrations of ciprofloxacin against Staphylococcus aureus.

Notes: Control PLA nanofiber mat a); PLA nanofiber mat $(0.15 \mu \mathrm{g} / \mathrm{mL})$ b); PLA nanofiber mat $(0.3 \mu \mathrm{g} / \mathrm{mL}) \mathrm{c})$; PLA nanofiber mat $(0.45 \mu \mathrm{g} / \mathrm{mL}) \mathrm{d})$; and PLA nanofiber mat $(0.55 \mu \mathrm{g} / \mathrm{mL})$ e).

Abbreviations: PLA, polylactide; SD, standard deviation.

growth in Figure 10A, and S. aureus were completely absent in Figure 10B. Figure 10C shows the appearance of $E$. coli growth, and Figure 10D shows the absence of the $E$ coli.

The functionality of ciprofloxacin release was investigated using $S$. aureus inhibition experiments. S. aureus is a Gram-positive, spherical bacterium, typically found in skin, nasal passages, and mucous scaffolds, and can cause a wide range of supportive infections. This bacterium was chosen because it is the most likely to induce infections during surgery and in wounds. Pure and released ciprofloxacin from the nonwoven nanofibers at different concentrations were introduced into $5 \mathrm{~mL}$ bacterial aliquots as reference, and the ability of each sample to inhibit bacterial growth was evaluated. Bacterial growth was monitored by the absorbance at $625 \mathrm{~nm}$ in ultraviolet-visible spectroscopy.

Bacterial aliquots were inoculated with the released drug solutions at concentrations corresponding to those for the stock drug.

As seen in Figure 8, it is apparent that both pure and released drug is equally effective at suppressing $S$. aureus growth at the specific concentrations tested. These results confirmed that the release of ciprofloxacin from the nonwoven nanofiber mat retains its biological function and that the process of electrospinning has no adverse effect on changing the structure of conjugated or incorporated ciprofloxacin.

The effectiveness of electrospun nonwoven nanofiber with and without ciprofloxacin was tested to examine the
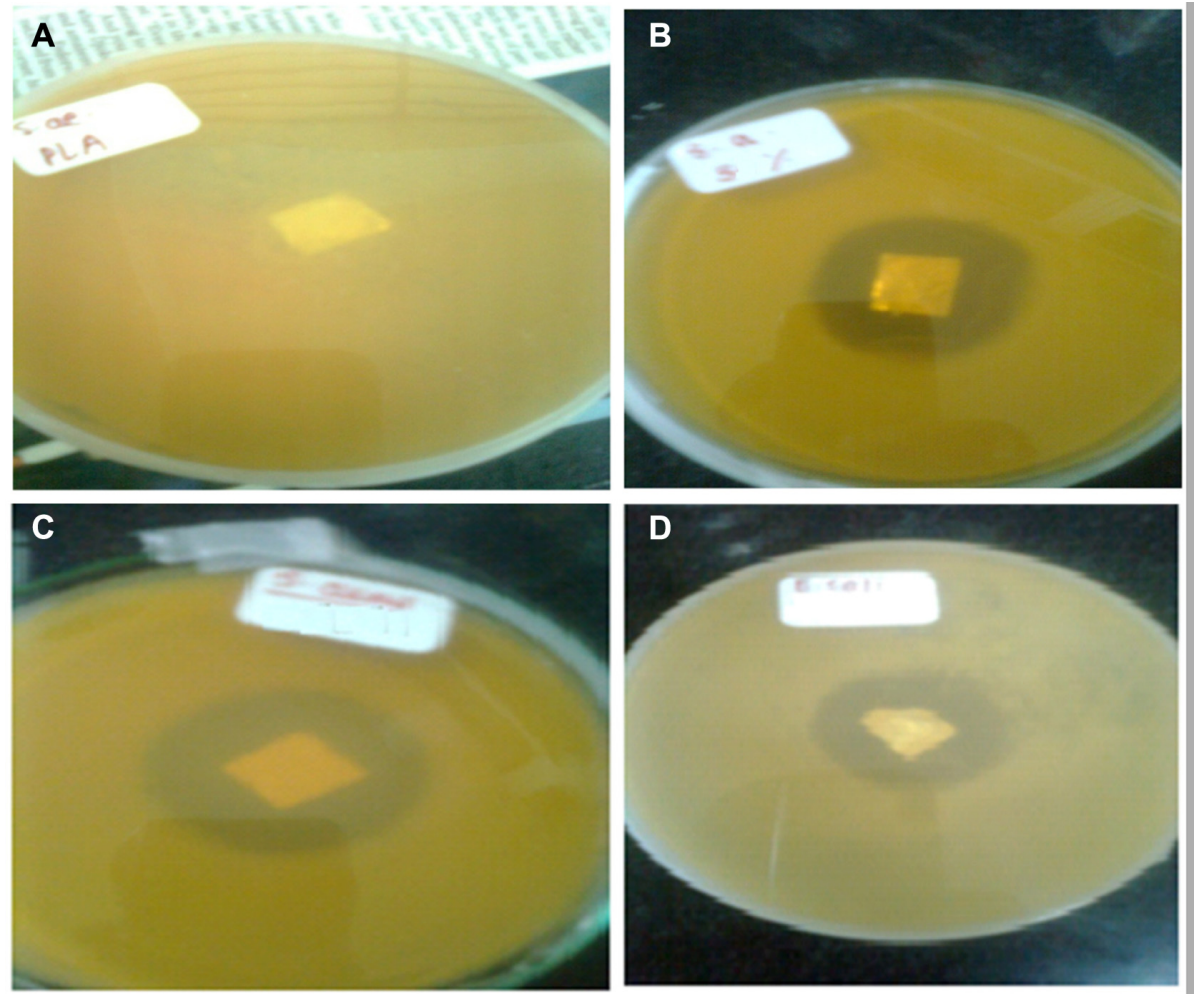

Figure 9 Antibacterial performances of PLA and ciprofloxacin-conjugated PLA nanofibers.

Notes: Staphylococcus aureus on PLA nonwoven electrospun mat (A); Staphylococcus aureus on PLA-CP nonwoven electrospun mat (B); Escherichia coli on PLA nonwoven electrospun mat (C); Escherichia coli on PLA-CP nonwoven electrospun mat (D).

Abbreviations: PLA, polylactide; PLA-CP, ciprofloxacin-conjugated PLA. 
Table I Ciprofloxacin release in the presence of Escherichia coli at various times

\begin{tabular}{ll}
\hline Time (hours) & $\begin{array}{l}\text { Growth inhibition } \\
\text { area (\%) }\end{array}$ \\
\hline 1 & 99.22 \\
3 & 99.33 \\
6 & 99.73 \\
18 & 99.94 \\
24 & 100 \\
78 & 100 \\
\hline
\end{tabular}

drug's ability to inhibit bacterial growth in a dynamic system (nanofiber mixed with bacterial liquid cultures).

Data presented in Figure 9 clearly show that the drug containing nanofiber mats are effective in inhibiting bacterial growth. The electrospun mat containing $0.55 \mu \mathrm{g} / \mathrm{mL}$ of ciprofloxacin completely eliminated the bacterial population in solution. Figure 9 shows an absolute control and $100 \%$ inhibition of bacterial growth. All data are normalized to this absorbance reading.

In addition to the liquid bacterial culture test, the efficiency of the nanofiber mats using a static system for
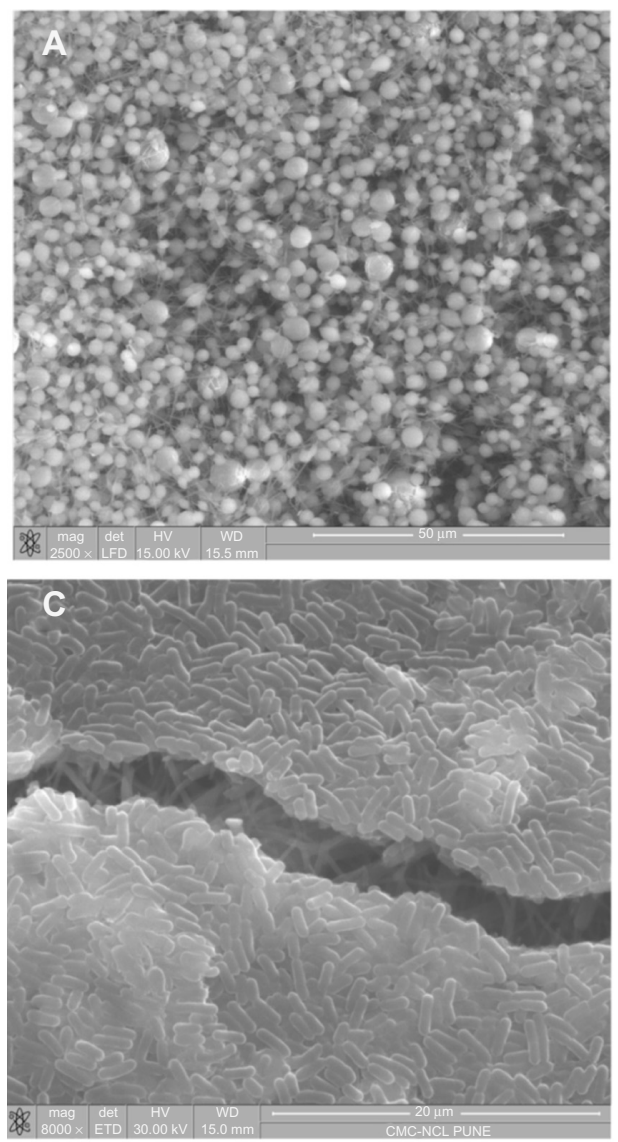

bacterial growth on agar plates was also examined, as shown in Figure 10A-D. The growth of $S$. aureus bacteria was visualized to assess the viability of the nanofiber mats. An agar region where the mat was placed, clearly shows inhibition of bacterial growth after 24 hours of incubation at $37^{\circ} \mathrm{C}$. Additionally, the drug release from the drug containing nanofiber mat $\left(1 \times 1 \mathrm{~cm}^{2}\right)$ also inhibited bacterial growth in a much larger area than the control mat due to diffusion of the ciprofloxacin onto the agar. In contrast, the PLA nanofiber mat containing no drug exhibited robust bacterial growth. It is interesting to note that the drug potency decreased with respect to time.

Figure 10A and B show the SEM images of PLA nanofiber mats without drug and with drug. The same mat was incubated in the presence of $S$. aureus for 24 hours. Thereafter, it was gently washed and dried, and SEM images of this mat were recorded. The PLA mat without drug showed robust $S$. aureus proliferation, while the PLA nanofiber mat containing ciprofloxacin showed complete inhibition of bacterial growth. These results showed that the ciprofloxacin released
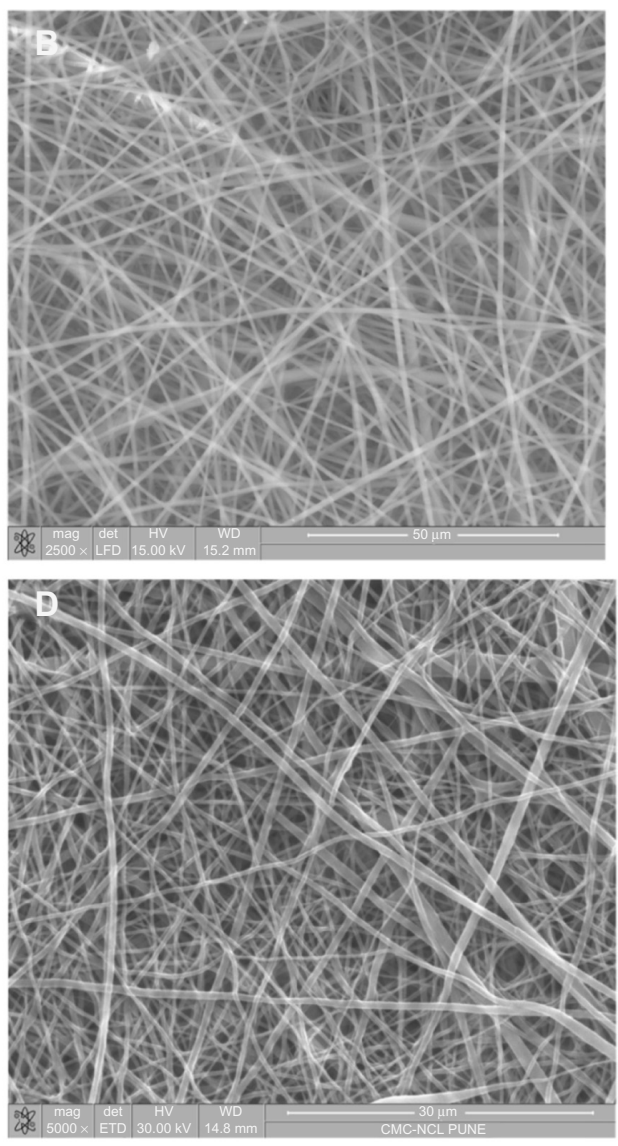

Figure 10 SEM images of PLA and PLA-CP nanofiber mats with bacteria.

Notes: PLA-CP mat with Staphylococcus aureus (A); PLA-CP mat without Staphylococcus aureus. (B); PLA-CP mat with Escherichia coli (C); PLA-CP-mat without Escherichia coli (D).

Abbreviations: PLA, polylactide; PLA-CP, ciprofloxacin-conjugated PLA; SEM, scanning electron microscope. 
from the drug-conjugated nanofiber possesses antimicrobial activity against $S$. aureus bacteria. This again shows that the activity of ciprofloxacin is not lost during the following exposure to solvents, heat, and chemicals encountered during the synthesis and fabrication of drug-conjugated polymer using electrospinning. Similarly, the same mat was incubated in the presence $E$. coli for 24 hours, and SEM images were recorded (Figure 10C and D).

The mechanism of action of ciprofloxacin may also be rationalized according to the result of antibacterial activity. Quinolines, including ciprofloxacin, inhibit the activity of the bacterial enzyme, DNA gyrase, which leads to bacterial cell death. ${ }^{37,38}$ The drug may bind to specific portions of the bacterial DNA during protein synthesis. ${ }^{39}$ Shen et $\mathrm{al}^{40}$ reported that the quinoline molecules form super molecules through $\mathrm{H}^{+}$bonding.

\section{Drug release kinetics}

Hydrolysis studies were carried out to evaluate the ciprofloxacin release from nonwoven nanofiber mats under different conditions. An indicator of this is the lower $\mathrm{pH}$ of venous blood (7.35) compared to that of arterial blood (7.45). The $\mathrm{pH}$ of intact skin ranges from about 4.8 to 6.0, while the interstitial fluid exhibits a near neutral $\mathrm{pH}$. If wound healing is to be initiated, then it is important that the wound is maintained above $\mathrm{pH} 4$, given that the enzymes are essential for wound healing. Modulation of protease activity may therefore be significant in accelerating wound healing. ${ }^{17}$

The study was performed by incubation of nanomat in buffer solution of $\mathrm{pH} 1,5.9,7.0$, and 7.4. The in vitro release

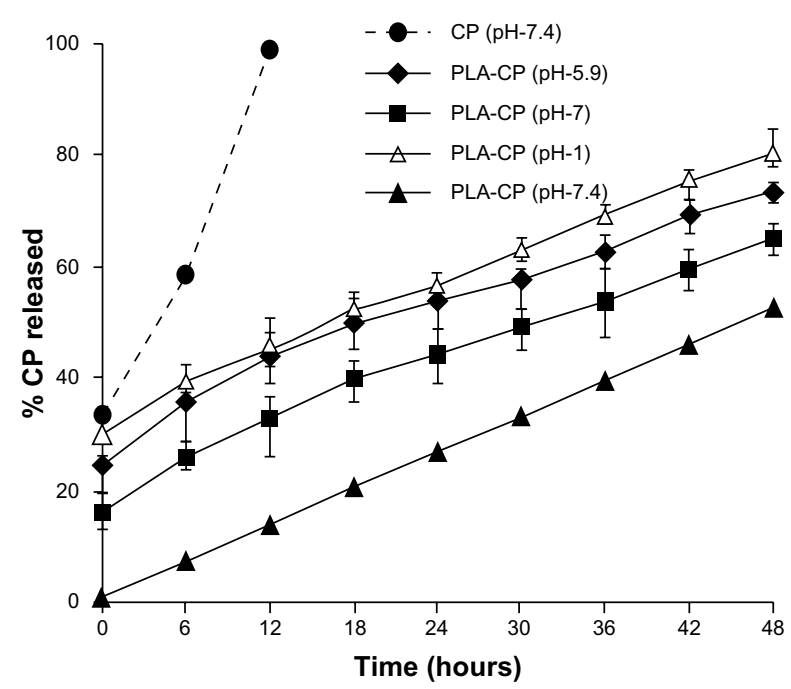

Figure I I Release of ciprofloxacin from PLA-CP conjugates under different $\mathrm{pH}$ conditions.

Abbreviations: CP, ciprofloxacin; PLA-CP, ciprofloxacin-conjugated polylactide. profile of nanomat is shown in Figure 11. PLA conjugates underwent faster ciprofloxacin release at $\mathrm{pH} 1$ as compared to $\mathrm{pH} 5.9,7.0$, and 7.4. In a 48-hour period, the release of drug was $85 \%$ at $\mathrm{pH} 1$ and $55 \%$ at $\mathrm{pH} 7.4$, which is comparatively slower than that of $\mathrm{pH} 1$. The moderate drug releases at pH 5.9 and 7.0 in 48 hours are $68 \%$ and $79 \%$, respectively. It was determined that the rates of ciprofloxacin release for the PLA conjugate nonwoven nanofiber were $\mathrm{pH}$ dependent.

The hydrolytic degradation of polymer involves the chemical scission at an ester linkage by a water molecule. Water molecules can easily penetrate into the structure because of the nonwoven nanofabricated mat and can hydrolyze the ester bond. In conclusion, the release rate is highly dependent on the ester segment in the PLA and $\mathrm{pH}$ of the medium.

Kinetics of the biodegradation of polyester conjugate and the cytotoxicity tests (3-[4,5-Dimethylthiazol-2-yl]-2,5diphenyltetrazolium bromide assay) are still under investigation, and we intend to present and discuss those findings in a future report.

\section{Conclusion}

We reported a biocompatible zinc prolinate catalyst for preparation of PLA $(>100,000)$ and PLA-CP. The ciprofloxacin was covalently bonded to the chain end of two-, three-, fourarm PLA as an ester linkage via the piperazine ring. The concentration of ciprofloxacin was varied using telechelic (two-, three-, four-, six-arm, and star-shaped) PLA polymer as a starting material. The electrospun nonwoven nanofibers of high molecular weight PLA and drug containing PLA were fabricated. SEM images show nanofibers in the range of 150-400 $\mathrm{nm}$ and nonporous structure ranging from $62-102 \mathrm{~nm}$, without changing the activity of the ciprofloxacin. In vitro studies were carried out to evaluate the ciprofloxacin release from nonwoven nanofiber mats under different $\mathrm{pHs}(1,5.9,7.0$, and 7.4). The release rate was observed to be highly dependent on the ester segment in the PLA and $\mathrm{pH}$ of the medium.

The released ciprofloxacin from PLA nonwoven nanofiber was found to be structurally intact as well as effective in its ability to inhibit bacterial growth ( $S$. aureus and $E$. coli) in both a static (agar) and dynamic (liquid) environment. This method can potentially be extended to the fabrication of drug-conjugated nonwoven nanofiber mat for the application in drug delivery systems.

\section{Acknowledgment}

Sharad P Parwe (Junior Research Fellow) gratefully acknowledges the Department of Biotechnology, New Delhi, India for financial support. 


\section{Disclosure}

The authors report no conflicts of interest in this work.

\section{References}

1. Jagur-Grodzinski J. Biomedical application of functional polymers. React Funct Polym. 1999;39(2):99-138.

2. Uhrich KE, Cannizzaro SM, Langer RS, Shakesheff KM. Polymeric systems for controlled drug release. Chem. Rev. 1999;99(11): 3186-3198.

3. Merkli A, Tabatabay C, Gurny R, Heller J. Biodegradable polymers for the controlled release of ocular drugs. Prog Poly Sci. 1998;23(3): $563-580$.

4. Ueda H, Tabata Y. Polyhydroxyalkanonate derivatives in current clinical applications and trials. Adv Drug Deliv Rev. 2003;55(4): 501-518.

5. Albertsson AC, Varma IK. Recent developments in ring opening polymerization of lactones for biomedical applications. Biomacromolecules. 2003;4(6):1466-1486.

6. Storey RF, Sherman JW. Kinetics and mechanism of the stannous octoate-catalyzed bulk polymerization of $\varepsilon$-caprolactone. Macromolecules. 2002;35(5):1504-1512.

7. Okada M. Chemical syntheses of biodegradable polymers. Prog Poly Sci. 2002;27(1):87-133.

8. Kowalski A, Duda A, Penczek S. Mechanism of cyclic ester polymerization initiated with tin(II) octoate. Macromolecules fitted with tin(II) alkoxide species observed directly in MALDI-TOF spectra. Macromolecules. 2000;33(3):689-695.

9. Sobczak M, Kolodziejski W. Polymerization of cyclic esters initiated by carnitine and tin (II) octoate. Molecules. 2009;14(2):621-632.

10. Duda A, Biela T, Kowalski A, Libiszowski J. Amines as (co)initiators of cyclic esters' polymerization. Polimery. 2005;50(7-8):501-508.

11. Cai Q, Zhao Y, Bei J, Xi F, Wang S. Synthesis and properties of star-shaped polylactide attached to poly(amidoamine) dendrimer. Biomacromolecules. 2003;4(3):828-834.

12. Kobayashi S, Uyama H, Kimura S. Enzymatic polymerization. Chem Rev. 2001;101(12):3793-3818.

13. Lee SH, Hyun Kim S, Han YK, Kim YH. Synthesis and degradation of end-group-functionalized polylactide. J Poly Sci Part A. 2001;39(7): 973-985.

14. Williams CK, Breyfogle LE, Choi SK, et al. A highly active zinc catalyst for the controlled polymerization of lactide. J Am Chem Soc. 2003;125(37):11350-11359.

15. Sobczak M. Synthesis and characterization of polyester conjugates of ciprofloxacin. Eur J Med Chem. 2010;45(9):3844-3849.

16. Caço AI, Varanda F, Pratas de Melo MJ, Dias AMA, Dohrn R, Marrucho IM. Solubility of antibiotics in different solvents. Part II. Non-hydrochloride forms of tetracycline and ciprofloxacin. Ind Eng Chem Res. 2008;47(21):8083-8089.

17. Tsou TL, Tang ST, Huang YC, Wu JR, Young JJ, Wang HJ. Poly(2hydroxyethyl methacrylate) wound dressing containing ciprofloxacin and its drug release studies. J Materials Sci. 2005;16:95-100.

18. Unnithan AR, Barakat NA, Pichiah PB, et al. Wound-dressing materials with antibacterial activity from electrospun polyurethane-dextran nanofiber mats containing ciprofloxacin HCl. Carbohydr Polym. 2012;90(4): 1786-1793.

19. Parshikov IA, Heinze TM, Moody JD, Freeman JP, Williams AJ, Sutherland JB. The fungus Pestalotiopsis guepini as a model for biotransformation of ciprofloxacin and norfloxacin. Appl Microbiol Biotechnol. 2001;56(3-4):474-477.

20. Md-Saleh SR, Chilvers EC, Kerr KG, et al. Synthesis of citrateciprofloxacin conjugates. Bioorg Med Chem Lett. 2009;19(5): 1496-1498.
21. Parshikov IA, Freeman JP, Lay JO, Beger RD, Williams AJ, Sutherland JB. Microbiological transformation of enrofloxacin by the fungus Mucor ramannianus. Appl Environ Microbiol. 2000;66(6):2664-2667.

22. Sobczak M. Synthesis and characterization of polyester conjugates of ciprofloxacin. Eur J Med Chem. 2010;45(9):3844-3849.

23. National Committee for Clinical Laboratory Standards. Methods for Dilution Antibacterial Susceptibility Tests for Bacteria that Grow Aerobically - Fifth Edition: Approved Standard M7-A5. Wayne PA: NCCLS; 2000.

24. Melo MJP, Varanda FR, Dohrn R, Marrucho IM. Solubility of ciprofloxacin and moxifloxacin in different solvents: the effect of the $\mathrm{HCl}$ group. Proceedings of the EMPROMER, 2nd Mercosur Congress on Chemical Engineering and 4th Mercosur Congress on Process Systems Engineering; August 14-18; 2005, Rio de Janeiro, Brazil.

25. Park KE, Lee KY, Lee SJ, Park WH. Surface characteristics of plasma-treated PLGA nanofibers. Macromol Sym. 2007; 249-250(1):103-108.

26. Xu CY, Inai R, Kotaki M, Ramakrishna S. Aligned biodegradable nanofibrous structure: a potential scaffold for blood vessel engineering. Biomaterials. 2004;25(5):877-886.

27. Woo GL, Mittelman MW, Santerre JP. Synthesis and characterization of a novel biodegradable antimicrobial polymer. Biomaterials. 2000;21(12):1235-1246.

28. Drlica K, Zhao X. DNA gyrase, topoisomerase IV, and the 4-quinolones. Microbiol Mol Biol Rev. 1997;61(3):377-392.

29. Ashammakhi N, Veiranto M, Suokas E, Tiainen J, Niemelä SM, Törmälä P. Innovation in multifunctional bioabsorbable osteoconductive drug-releasing hard tissue fixation devices. J Mater Sci Mater Med. 2006;17(12):1275-1282.

30. Koort JK, Makinen TJ, Suokas E, et al. Sustained release of ciprofloxacin from an osteoconductive poly(DL)-lactide implant. Acta Orthop. 2008;79(2):295-301.

31. Nagy L, Ishii K, Karatas A, et al. Water dissection technique of Toth for opening neurosurgical cleavage planes. Surg Neurol. 2006;65(1):38-41; discussion 41

32. Martinez B, Lairion F, Pena MB, Di Rocco P, Nacucchio MC. In vitro ciprofloxacin release from poly(lactide-co-glycolide) microspheres. J Microencapsul. 1997;14(2):155-161.

33. Darbre T, Machuqueiro M. Zn-proline catalyzed direct aldol reaction in aqueous media. Chem Commun (Camb). 2003;9:1090-1091.

34. Buschle-Diller G, Cooper J, Xie Z, Wu Y, Waldrup J, Ren X. Release of antibiotics from electrospun bicomponent fibers. Cellulose. 2007:14:553-552.

35. Wachsen O, Reichert KH, Kruger RP, Much H, Schulz G. Thermal decomposition of biodegradable polyesters, 3 Studies on the mechanism of thermal degradation of oligo-L-lactide using SEC, LACCC and MALDI-TOF MS. Polymer Degrad Stabil. 1997;55:225-231.

36. Nielen MWF. MALDI TOF mass spectrometry of synthetic polymers. Mass Spectrometry Rev. 1999;18:309-344.

37. Venugopal RS. Application of polymer nanofibers in biomedicine and biotechnology. Appl Biochem Biotechnol. 2005;125(3):147-157.

38. Shen LL. Quinoline-DNA interaction. In: Hooper DC, Rubinstein E, editors. Quinolone Antimicrobial Agents. 2nd ed. Washington, DC: American Society for Microbiology. 1993;77-95.

39. Hooper DC, Wolfson JS. Mechanisms of quinolone action and bacterial killing. In: DC Hooper, Rubinstein E, editors. Quinolone Antimicrobial Agents. 2nd ed. Washington, DC: American Society for Microbiology. 1993;53-75.

40. Shen LL, Mitscher LA, Sharma PN, et al. Mechanism of inhibition of DNA gyrase by quinolone antibacterials: a cooperative drug - DNA binding model. Biochemistry. 1989;28(9):3886-3894. 
International Journal of Nanomedicine

Dovepress

\section{Publish your work in this journal}

The International Journal of Nanomedicine is an international, peerreviewed journal focusing on the application of nanotechnology in diagnostics, therapeutics, and drug delivery systems throughou the biomedical field. This journal is indexed on PubMed Central, MedLine, CAS, SciSearch $®$, Current Contents ${ } /$ Clinical Medicine,
Journal Citation Reports/Science Edition, EMBase, Scopus and the Elsevier Bibliographic databases. The manuscript management system is completely online and includes a very quick and fair peer-review system, which is all easy to use. Visit http://www.dovepress.com/ testimonials.php to read real quotes from published authors.

Submit your manuscript here: http://www.dovepress.com/international-journal-of-nanomedicine-journal 